\title{
A FLUID FLOW ANALYSIS OF A JET EJECTOR SYSTEM USED IN INDUSTRIAL APPLICATIONS
}

\author{
OLARU IONEL ${ }^{* 1}$ \\ I "Vasile Alecsandri" University of Bacau, Calea Marasesti 157, Bacau, 600115, Romania
}

\begin{abstract}
Many studies have been conducted for jet ejectors used in the recovery of solar energy or for their use in refrigeration systems for various industrial applications. Generally, these types of ejectors are using water as the working fluid because water have a low cost, a chemical stability and is safe to use. Naturally, other refrigerants, with largescale application for industry, can be used. In such a type of jet ejector, besides selection of the refrigerant, the design of ejector is very important, with strongly influence to the performance, because the compression ratio depends on the geometry of the nozzle and on the geometry of the diffuser. Compared to other refrigeration systems, those with ejector have some advantages: simplicity in construction, high liability and low cost. However, it has a coefficient of performance lower than conventional systems, this limited the widespread application of ejector refrigeration systems.
\end{abstract}

Keywords: jet, ejector, fluid, flow, heat, recuperation

\section{INTRODUCTION}

Recently researchers have tried to find a wider application of jet ejector systems, in refrigeration and air conditioning applications by using reduced amounts of thermal energy, such as that resulting from solar energy and waste heat of various industrial processes [1].

Some studies have shown that by using a variable geometry of the ejectors may achieve a high performance thereof in different operating conditions. One such refrigeration system with jet ejector consists of: pressure generator, evaporator, condenser, expansion vessel, jet ejector and a circulation pump [2, 3].

In this system, the fluid with a high pressure which comes from the generator passes through the fluid jet ejector and drives the fluid with low pressure coming from the evaporator. The both fluids are mixed in the ejector center and recover a part of pressure in the ejector diffuser; fluid goes then in the condenser [4].

The condense is divided in two parts: one part is pumped back to the generator, the other part flows through the expansion vessel and enters into the evaporator, the vapor flows again through the jet ejector thus is ended a refrigeration cycle system [5].

If the entire cycle is examined, can be observed that the system obtain heat from the heat source in the generator using the circulating pump, thereby the system produces a cooling effect in the evaporator and then dissipates the heat to the environment through the condenser, Figure 1 [6].

\footnotetext{
* Corresponding author, email: ionelo@ub.ro

(C) 2020 Alma Mater Publishing House
} 
From this study we conclude that the ejector is the key component in the refrigeration cycle, the analysis and the optimization of its design can improve overall system performance.

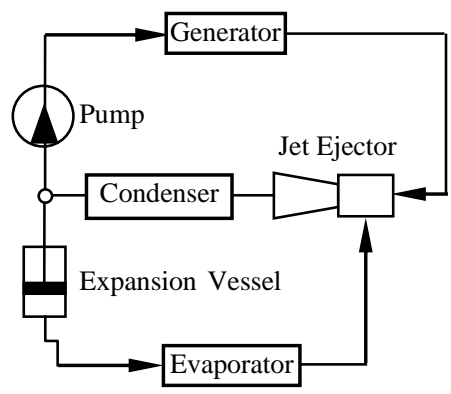

Fig. 1. Jet Ejector system.

In this paper we propose to analyze the process from inside the jet ejector in term to optimize its geometry parameters by analyzing the variation of working fluid flow parameters from inside, entire behavior from the inlet to the ejector outlet.

\section{ANALYSIS SETUP}

The steam jet ejectors are technological devices that generate vacuum, they are found in various applications in the industry. Due to the fact that they have no moving elements, they do not require expensive maintenance, they can be manufactured from almost any material and can be used in any industrial application [7].

The ejectors can be designed with different working fluids of which the cheapest are water and steam. They can be successfully used in petrochemical processes, thermal compressors, in the food industry for the deodorization of edible oil and in any other system that uses vacuum.

Therefore, an ejector is a type of vacuum pump or compressor. In a steam jet ejector, the suction chamber is connected to the motive chest by means of a flange. The Venturi type diffuser is also composed of two conical areas joined in the middle by means of flanges. All these things are necessary to be able to configure the whole system according to our needs, Figure 2 [8].
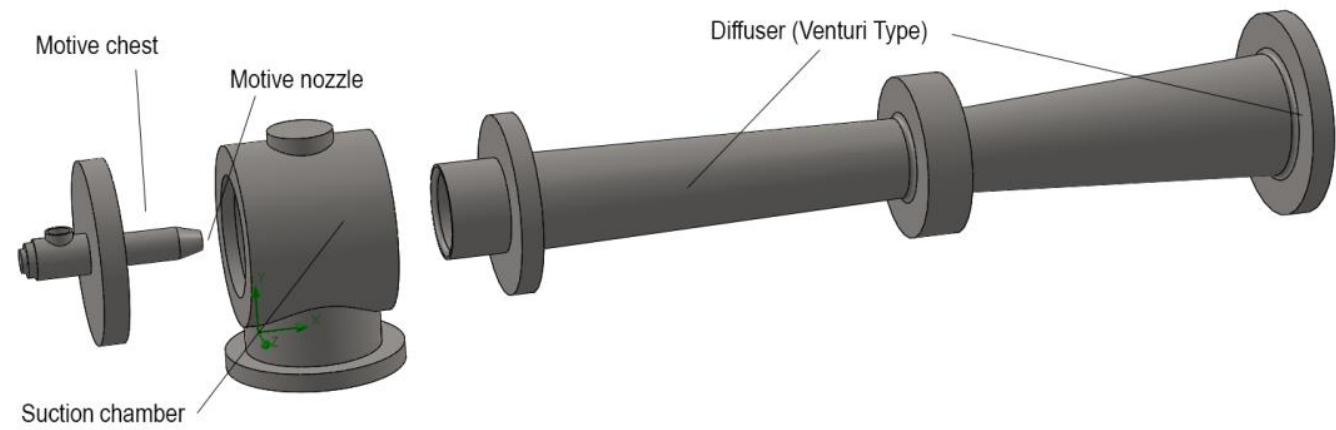

Fig. 2. The Jet Ejector components.

As the air is driven by steam, the mixture passes through the ejector into a Venturi type diffuser. In the nozzle, its velocity energy is converted to pressure energy, which helps to discharge the mixture a preset output pressure. This output of the mixture can either be discharged into the atmosphere or sent further to a capacitor, Figure 3.

As we have established in the introduction, the steam jet vacuum systems combine ejectors, capacitors and interconnecting pipes to ensure phase ejection. These systems operate on the ejector-Venturi principle, which relies on the impulse of a high-speed steam jet to move air and other gases from a pipeline or connecting vessel.

If we analyze the nozzle through which the steam is sent under pressure, we see that it is composed of several components: steam inlet chamber through which the steam is introduced, this room is provided with a stopper to 
prevent the steam to leaving this room. Instead, as needed, it can be replaced with a pipe through which to enter another working fluid, so that there is a pre-mix in this first room.

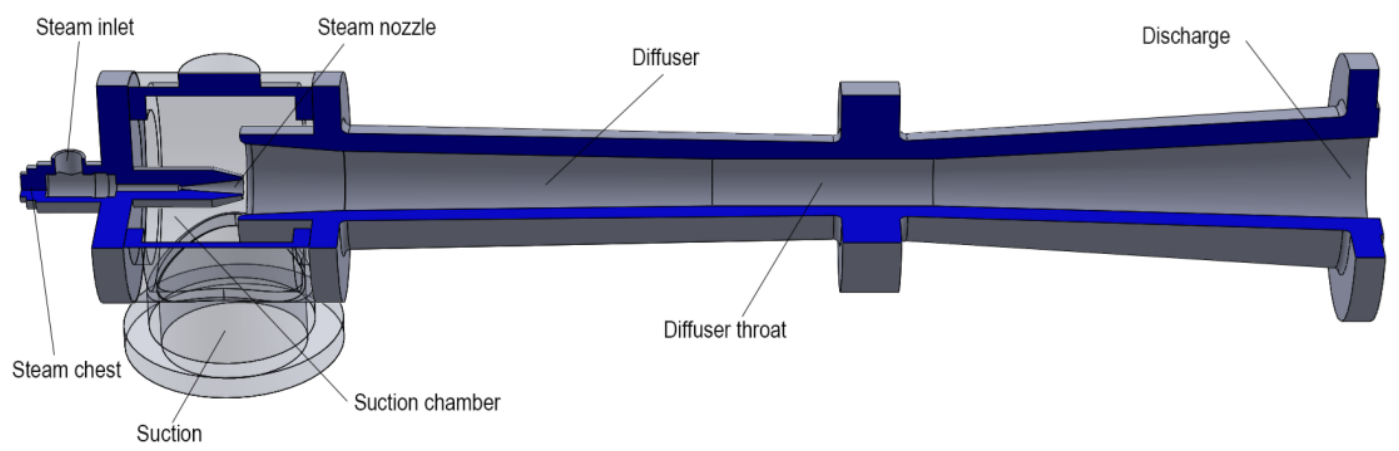

Fig. 3. The Jet Ejector assembly.

If necessary, the initial nozzle can be provided with an extension pipe for the entire assembly, Figure 4 on which the converging nozzle is assembled from the final section [8]. The extension part is required to control the discharge of the jet under pressure in the vacuum chamber.

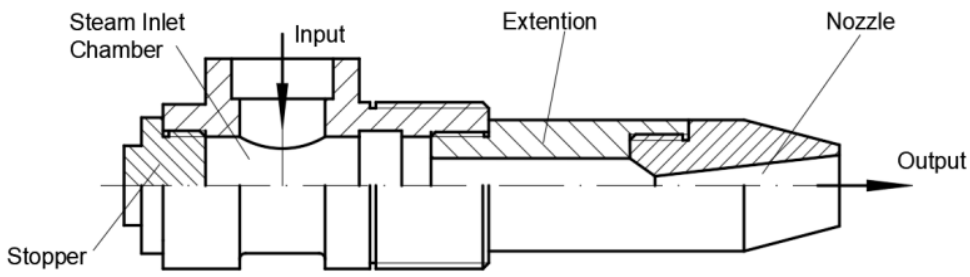

Fig. 4. Pressured steam nozzle.

All this initial assembly is connected to the whole assembly by a connecting flange which is threaded at one end of the suction chamber. This nozzle sends the pressure steam further into the suction chamber, it creates a vacuum that entails another working fluid and mixes them, so that the resulting fluid is then passed through the Venturi diffuser.

\section{RESULTS AND DISCUSSION}

From a constructive point of view, we have in Figure 5 a section through the ejector assembly. As mentioned above, the initial high-pressure nozzle is assembled by the mixing chamber by means of the flange with screws and nuts, as is the assembly of the two sections of the venturi type nozzle, as well as the connection between it and the main mixing chamber.

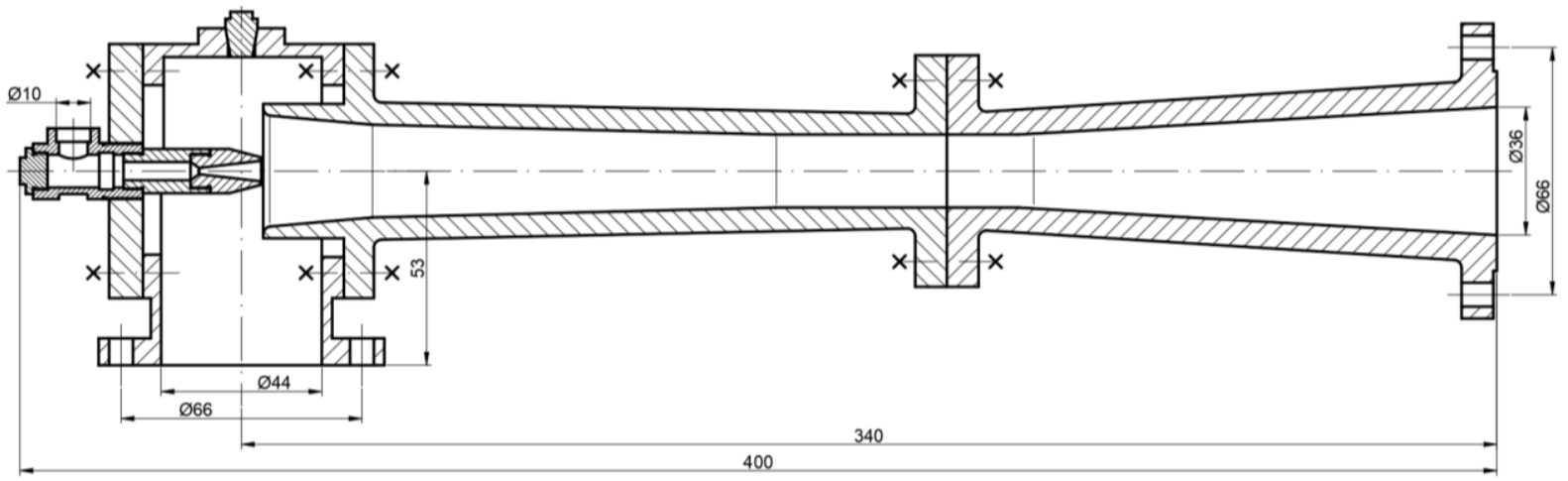

Fig. 5. Dimensional elements of the ejector. 
Because the capacity of a single ejector is determined by its dimensions, a single unit has practical limits on total compression and the flow it can deliver. For greater compression, two or more ejectors can be arranged in series. For greater fluid flow capacity, two or more ejectors should be arranged in parallel.

In a multi-stage system, capacitors are typically used between successive ejectors. By condensing the vapors before sending the flow to the next step, the fluid load is reduced. This allows the use of smaller ejectors and thus reduces the main fluid consumption.

Within this work, an analysis was carried out through a specialized program Solidworks that has a module that can analyze the flow of fluids through different bodies. After the three-dimensional realization of the whole assembly was simulated a real situation whereby a steam was sent with a pressure of 5 bars through the initial nozzle [9].

The secondary fluid that is absorbed in the suction chamber has a pressure close to atmospheric pressure. As mentioned, this steam under pressure is mixed with the fluid that is sucked through the suction chamber and sent through the convergent divergent nozzle into the system.

Figure 6 a show the distribution of velocities through the entire ejector. Figure $6 \mathrm{~b}$ shows the distribution of pressures in the initial nozzle area where of course the pressure is much higher than the whole system. In order to visualize the lines of current and the way in which the workflows meet and mix in the suction chamber, the image $6 \mathrm{c}$ was captured [10].

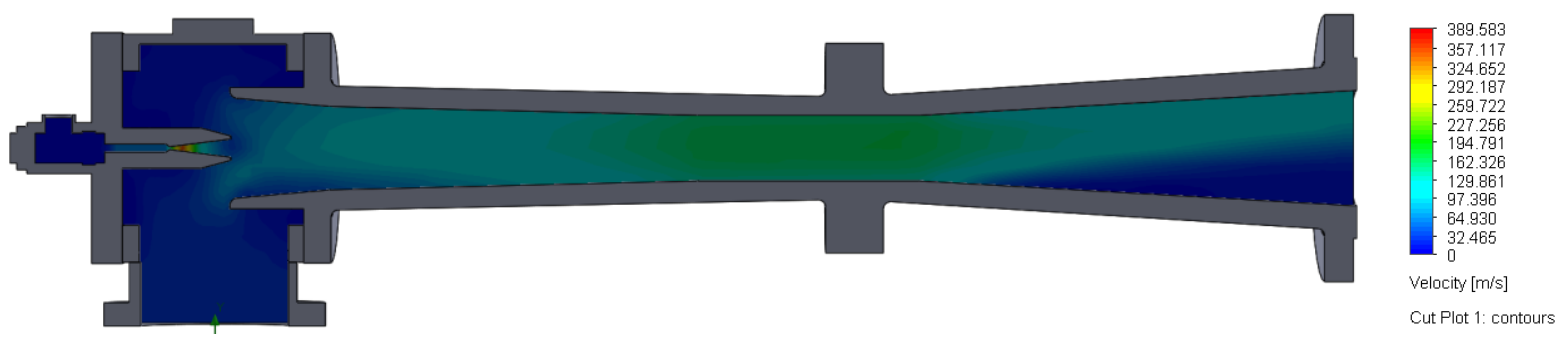

a.

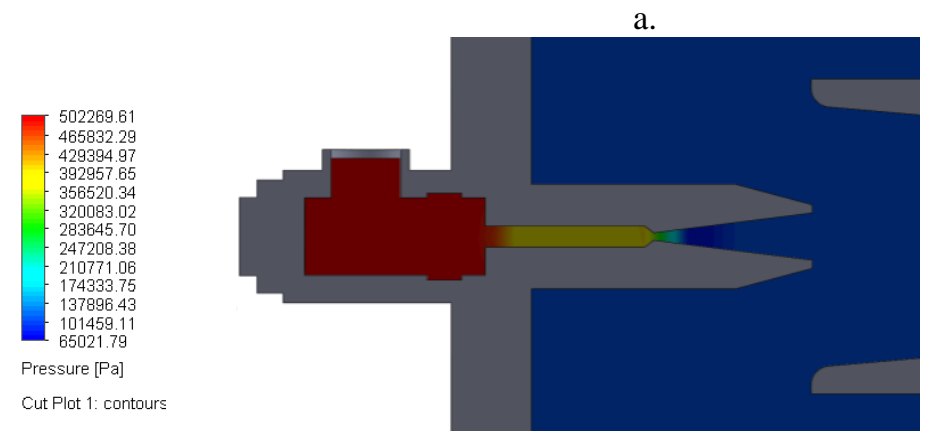

b.

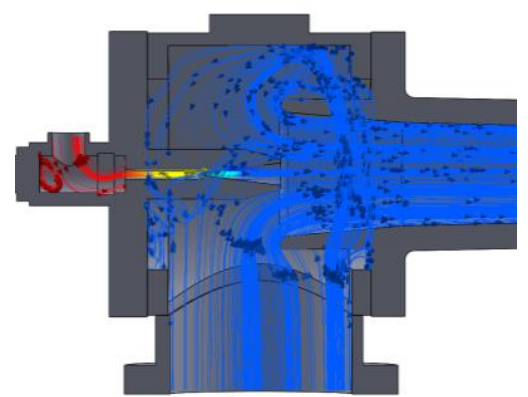

c.

Fig. 6. Ejector's fluid flow parameters: a. velocity; b. pressure; c. fluid flow lines.

Thus, they could be extracted from the suction pressure analysis in relation to the equivalent vapor load calculated at room temperature, Figure 7 a. The characteristic curves of the flow parameters related to the main axis of the ejector are shown in Figure 7 b. pressure distribution and velocity along the ejector studied.

In the first interval we can observe an increase of the initial fluid velocity through the pressure nozzle, as the fluid velocity increases, the initial pressure decreases steadily along the initial assembly. In the mixing chamber, there is a constant approximate level of the respective velocities for the pressures, because here it performs a relaxation of the steam initially introduced in the ejector.

A third section is the one due to the Venturi type at the end of this section the pressure will decrease and the velocity will increase in this area due to its divergent convergent section, following that in the final section they will relax following these fluids to be sent further in the installation. 
In order to optimize these installations, in general the steam jet vacuum systems combine several ejectors, condensers and interconnecting pipes to ensure a control of the debt and the pressure of the working fluids, therefore an optimization of them, while maintaining low costs maintenance.

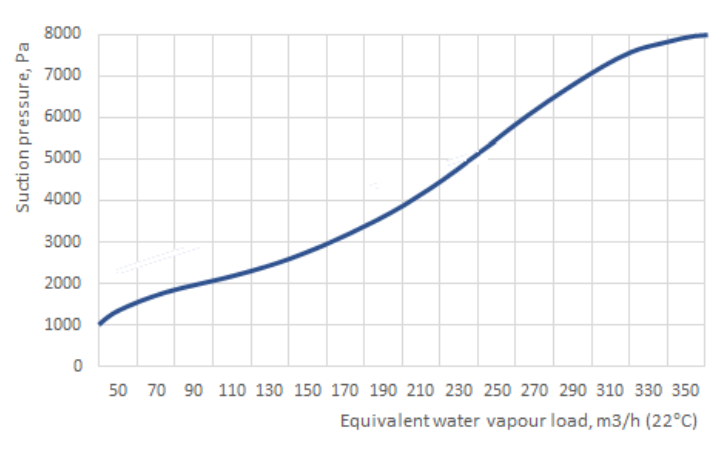

a.

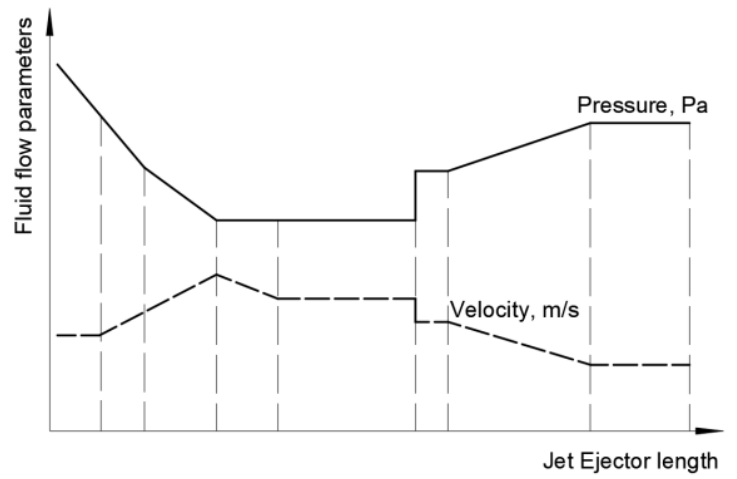

b.

Fig. 7. Fluid flow parameters in suction chamber: a. Ejector performance curve; a. Velocity and pressure distribution.

\section{CONCLUSIONS}

We concluded that the size of the ejector is the most important parameter for the effective performance of the ejector system. The dimensions of the ejector presented in the paper (single stage ejector) offer a better performance. A smaller nozzle exit area can avoid the loss of shock wave energy; it is also important to choose the Venturi type nozzle for the entire ejector to be as efficient as possible.

The main advantages of steam jet ejectors as compared to other types of vacuum units are first and foremost the low cost, they do not require moving parts which leads to their simple construction. Due to their simplicity, these ejectors are reliable, maintenance is simple and easy to build.

The ejection units can be made from any material that offers good corrosion and erosion resistance, being easy to install, does not require special foundations or special grips. However, the parameters of the ejectors may differ for their different geometries under the same operating conditions.

\section{REFERENCES}

[1] Selvaraju, A., Mani, A., Analysis of an ejector with environment friendly refrigerants, Applied Thermal Engineering, vol. 24, 2004, p. 827-838.

[2] Wenju, H., Meng-yuan, W., Jin-zhe, N., Yan, G., Qun-li, Z., The influence of ejectors structure parameters on the performance of ejector refrigeration system, Procedia Engineering, vol. 205, 2017, p. 2683-2690.

[3] Ruangtrakoon, N., CFD simulation on the effect of primary nozzle geometries for a steam ejector in refrigeration cycle, International Journal of Thermal Sciences, vol. 63, 2013, p. 133-145.

[4] Gutiérrez, A., León, N., Conceptual development and CFD evaluation of a high efficiency-variable geometry ejector for use in refrigeration application, Energy Procedia, vol. 57, 2014, p. 2544-2553.

[5] Saito, Y., Ito, T., Matsuo, A., Sato, H., Ejector configuration for designing a simple and high-performance solar cooling system, Energy Procedia, vol. 57, 2014, p. 2564-2571.

[6] Yapici, R., Experimental investigation of performance of vapor ejector refrigeration system using refrigerant R123, Energy Conversion and Management, vol. 49, 2008, p. 953-961.

[7] Rusly, E., Aye L., Charters, W., Ooi, A., CFD analysis of ejector in a combined ejector cooling system, International Journal of Refrigeration, vol. 28, no. 7, 2005, p. 1092-1101.

[8] https://www.graham-mfg.com/technical-documents-library/ejectors (10.04.2020).

[9] Olaru, I., A CFD Analysis in solidworks flow simulation for two mixing fluids with different temperatures in nozzles, Journal of Engineering Studies and Research, vol. 26, no. 1, 2020, p. 41-46.

[10] https://www.solidworks.com/sw/resources/getting-started-simulation-and-analysis-tools.htm (02.04.2020). 